\title{
HIV is an independent predictor of aortic stiffness
}

\author{
Oliver J Rider ${ }^{1,2^{*}}$, Mina Asaad ${ }^{1,2}$, Ntobeko Ntusi ${ }^{2}$, Emma Wainwright ${ }^{3}$, Genevieve Clutton ${ }^{3}$, Gemma Hancock ${ }^{3}$, \\ Rajarshi Banerjee ${ }^{1}$, Alex Pitcher ${ }^{2}$, Katherine Samaras ${ }^{4}$, Kieran Clarke ${ }^{1}$, Stefan Neubauer ${ }^{2,3}$, Lucy Dorrell ${ }^{3}$ \\ and Cameron J Holloway ${ }^{1,2,4}$
}

\begin{abstract}
Background: Patients with treated Human Immunodeficiency Virus-1 (HIV) infection are at increased risk of cardiovascular events. Traditionally much of this risk has been attributed to metabolic and anthropometric abnormalities associated with HIV, which are similar to the metabolic syndrome (MS), an established risk factor for cardiovascular mortality. It remains unclear whether treated HIV infection is itself associated with increased risk, via increase vascular stiffness.

Methods: 226 subjects (90 with HIV) were divided into 4 groups based on HIV and MS status: 1) HIV-ve/MS-ve, 2) HIV-ve/MS + ve, 3) HIV + ve/MS-ve and 4)HIV + ve/MS + ve. CMR was used to determine aortic pulse wave velocity (PWV) and regional aortic distensibility (AD).

Results: PWV was $11 \%$ higher and regional AD up to $14 \%$ lower in the HIV + ve/MS-ve group when compared to HIV-ve/MS-ve ( $p<0.01$ all analyses). PWV and AD in the HIV + ve/MS-ve group was similar to that observed in the HIV-ve/MS + ve group ( $p>0.99$ all analyses). The HIV + ve/MS + ve group had 32\% higher PWV and 30-34\% lower AD than the HIV-ve/MS-ve group (all $p<0.001$ ), and 19\% higher PWV and up to 31\% lower AD than HIV + ve/MS-ve subjects (all $p<0.05$ ). On multivariable regression, age, systolic blood pressure and treated HIV infection were all independent predictors of both PWV and regional AD.

Conclusion: Across multiple measures, treated HIV infection is associated with increased aortic stiffness and is also an independent predictor of both PWV and regional AD. The magnitude of the effect of treated HIV and MS are similar, with additive detrimental effects on central vascular elasticity.
\end{abstract}

Keywords: Aorta, Cardiovascular magnetic resonance, HIV

\section{Background}

Effective antiretroviral therapy has markedly improved life expectancy in the HIV-infected population. However, despite immunological modulation, aging with HIV is accompanied by an increased prevalence of metabolic abnormalities, atherosclerotic cardiovascular disease and higher all-cause mortality [1-4]. The pathogenesis of this accelerated atherosclerosis in HIV has not been fully elucidated. Even after adjusting for traditional risk factors, which tend to have a higher prevalence in the treated HIV population, elevated rates of coronary disease remain [2].

\footnotetext{
* Correspondence: oliver.rider@gmail.com

'Department of Physiology, Anatomy and Genetics, University of Oxford, Parks Road, Oxford OX1 3PT, UK

${ }^{2}$ Department of Cardiovascular Medicine, University of Oxford Centre for Clinical Magnetic Resonance Research, (OCMR), John Radcliffe Hospital, Oxford OX3 9DU, UK

Full list of author information is available at the end of the article
}

Recent studies have suggested that viral factors, in addition to traditional vascular risk factors, have independent negative effects, possibly by promoting atherogenic lipid abnormalities [5], monocyte attraction and migration into the vascular intima [6] and a chronic inflammatory state $[7,8]$, all of which produce an environment for accelerated atherogenesis.

In addition, treated HIV is associated with an increase in the prevalence of the cluster of metabolic risk factors that make up the metabolic syndrome [9]. Metabolic complications appear to result from treatments for HIV and, to some degree, from the effect of viral infection itself [10-13]. Whether viral factors amplify the atherogenic effect of traditional metabolic risk factors in HIV-infected individuals remains unclear.

Both aortic pulse wave velocity (PWV) and regional aortic distensibility (AD) are sensitive markers of aortic 
elastic function. Aortic pulse wave velocity is a clinical measure of arterial stiffness that has not only been shown to be predictive of both cardiovascular events and mortality in multiple population studies, [14,15] but is also a well-validated surrogate marker of atherosclerosis, corresponding closely to the degree of atherosclerosis as assessed by both computed tomography and post-mortem studies [16]. The aim of this study was to use PWV and AD to investigate 1 ) if HIV is independently associated with increased arterial stiffness, 2) the magnitude of the detrimental effect of HIV on aortic elastic function when compared to the metabolic syndrome and 3) whether or not the metabolic syndrome and HIV are additive in their detrimental effects.

\section{Methods}

\section{Study cohort}

90 patients with documented HIV infection (13 naive to antiretroviral therapy) and 136 subjects with no history of HIV infection were recruited to this study. Eligibility criteria were age over 18 years, no history or symptoms of cardiovascular disease and no contraindications to cardiovascular magnetic resonance (CMR). All patients with HIV were treated in accordance with national guidelines. Patients with HIV and non-infected subjects were subdivided into those with and without the metabolic syndrome according to the National Cholesterol Education Program-Adult Treatment Panel III (NCEP-ATP III) guidelines [17]. Subjects were diagnosed with the MS when at least 3 of 5 risk determinants increased waist circumference, increased systolic blood pressure (SBP) or diastolic blood pressure (DBP), elevated serum triglycerides, low high-density lipoprotein cholesterol (HDL-C), and impaired fasting glucose (IFG) were present. Subjects were then separated into 4 groups: 1) healthy controls without the MS (HIV-ve/MS-ve), 2) controls with the MS (HIV-ve/MS + ve), 3) patients with HIV without the MS (HIV + ve/MS-ve) and 4) patients with HIV and the MS (HIV + ve/MS + ve). This study was approved by the local ethics committee (ref. 10/H0604/95) and all subjects gave informed written consent prior to participation. Ethics was approved by the Oxford Research Ethics Committee.

\section{Anthropometric data}

Morning assessments took place after a minimum 10 hour fast. Height and weight were measured using a digital station (Seca, UK) and used to calculate body mass index (BMI, mass $(\mathrm{kg}) /$ height $\left.(\mathrm{m})^{2}\right)$. Waist circumferences were measured in the standing position at the level of the umbilicus with the average of three measurements taken. Data on duration of HIV infection, nadir CD4 count and Highly Active Antiretroviral Therapy
(HAART) were obtained from the treating physicians with the consent of the patients.

A fasting blood sample was obtained for measurement of plasma glucose, free fatty acids, hs-CRP, cholesterol and hs-CRP and were analysed by a commercial hospital laboratory. Insulin was measured using ELISA (Mercodia AB, Uppsala, Sweden). To calculate the homeostasis model assessment for insulin resistance (HOMA-IR) the following formula was used: fasting insulin $(\mathrm{pmol} / \mathrm{l}) \times$ fasting glucose $(\mathrm{mM} / \mathrm{l}) / 135$ and used as a measure of insulin resistance [18].

\section{CMR protocol for aortic distensibility}

All vascular imaging was performed at 1.5-Tesla (Avanto, Siemens Medical Solutions, Erlangen, Germany). Based on sagittal-oblique (candy cane) pilot images aligned with the aortic arch, thoracic aortic cine images were acquired in transverse planes at 3 levels as previously described: [19] the crossing of the pulmonary arch through 1) the ascending thoracic aorta (Ao), 2) proximal descending thoracic aorta (PDA) and 3) $12 \mathrm{~cm}$ below the PDA level piloted perpendicular to the orientation of the aorta (distal descending aorta, DDA). A brachial artery blood pressure was recorded during image acquisition to provide pulse pressure [20].

\section{CMR protocol for aortic pulse wave velocity}

To measure aortic PWV, images were acquired using a free-breathing, retrospectively ECG-gated, spoiled gradient echo sequence. Velocity-encoding gradient for phase contrast was applied to measure through-plane flow in the ascending aorta at the same three levels used for aortic distensibility. Oblique sagittal images were used to calculate the distance between the two imaging levels as previously described (Figure 1) [21].

\section{CMR protocols for visceral fat mass}

To measure visceral fat mass, a single breath-hold, single-slice, water-suppressed T1-weighted turbo spin echo sequence centred on L5 was acquired as previously described [22].

\section{Image analysis}

Image analysis was performed using Siemens analytical software (Argus @ , Siemens Medical Solutions, Erlangen, Germany). To analyse aortic PWV, flow images were manually contoured [23] and aortic PWV was determined as $\Delta \mathrm{x} / \Delta \mathrm{t}(\mathrm{m} / \mathrm{s})$, where $\Delta \mathrm{x}$ is the aortic distance between two imaging levels and $\Delta \mathrm{t}$ is time delay between the arrival of the foot of the pulse wave between these imaging levels (Figure 1) [24]. The arrival of the foot of the pulse wave was taken as the intersection of the tangent (determined by a least squares method of the four flow points around the half maximal point of flow) of the upslope of the flow 

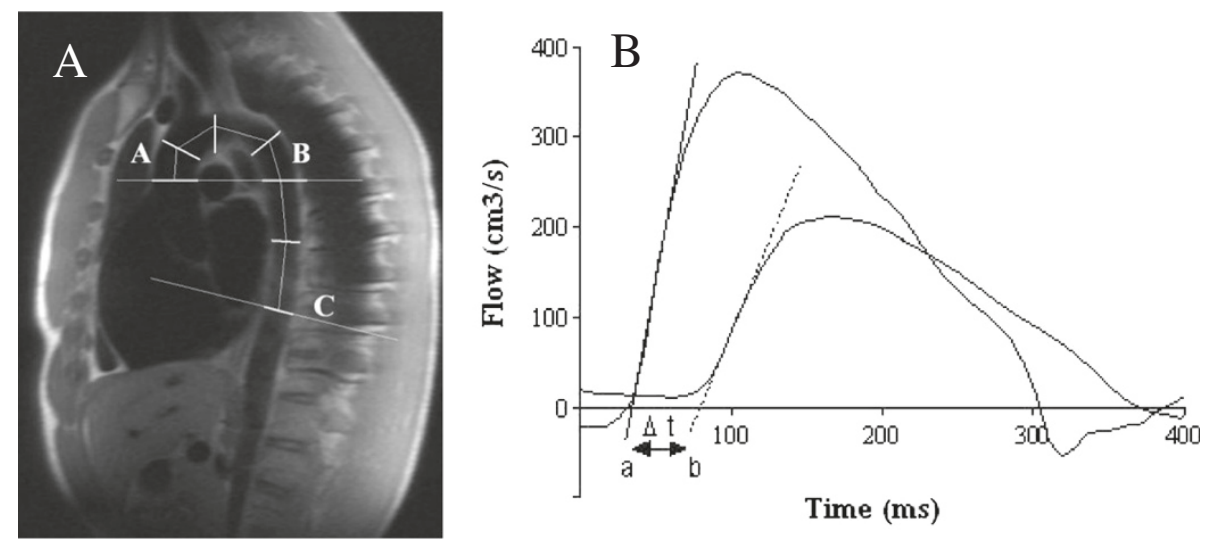

Time (ms)

Figure 1 Calculating pulse wave velocity. A. Distance $\Delta x$ was taken as the total distance between $\mathrm{A}$ (ascending aorta) and $\mathrm{C}$ (abdominal aorta). This was calculated using the sum of the distances between the centre points of lines drawn at $45^{\circ}, 90^{\circ}$ and $135^{\circ}$ to the scan level. B. Aortic flow/time curves used to calculate the arrival times of aortic pulse waveform. $\Delta$ t represents the time $(\mathrm{m} / \mathrm{s})$ between the intercepts $(\mathrm{b}$-a) of the tangents to the curve at the half maximal point of flow in the ascending aorta (a) and the abdominal aorta (b).

curve and the $\mathrm{x}$ (time) axis as previously described [19,24]. To assess visceral fat mass, transverse slices were manually countered as previously described [25].

\section{Statistical analysis}

All statistical analyses were performed using SPSS statistical software (version 19.0; SPSS Inc., Chicago, Ill, USA). Normality of distribution was assessed using the Kolmogorov-Smirnov test. Normally distributed data are presented as mean \pm standard deviation, nonnormally distributed data as median (interquartile range). Comparisons between normally distributed data in the 4 groups identified above were performed with one-way analysis of variance with post-hoc Bonferroni correction. Bivariate correlations for all subjects were calculated using Pearson correlation coefficients. Significance was assumed at a probability value of $\mathrm{p}<0.05$. Variables with $\mathrm{p}<0.05$ and the strongest relationship with aortic pulse wave velocity and $\mathrm{AD}$ were then included as independent variables in forced entry stepwise multiple regression analysis with aortic PWV and AD as the dependent variables.

\section{Results}

\section{Baseline characteristics of the study populations}

Anthropometric data for the study group when divided into the four groups is shown in Table 1. The immunological, virological and HAART status of patients with HIV are presented in Table 2.

\section{The effect of HIV on aortic elastic function}

To isolate the effect of HIV alone on aortic PWV and AD, patients with HIV but without the metabolic syndrome $(\mathrm{HIV}+\mathrm{ve} / \mathrm{MS}$-ve, $\mathrm{n}=73)$ were compared to non-infected subjects without the metabolic syndrome (HIV-ve/MS-ve, $\mathrm{n}=92$ ). The two groups were well matched for age, blood pressure, BMI, visceral fat, waist circumference, triglycerides, cholesterol, glucose, HOMA-IR and smoking status (Table 1). In agreement with the published literature, HIV infection was associated with reduced HDL cholesterol, a higher prevalence of smoking and an elevated high sensitivity C- reactive protein level (hs-CRP, Table 1). PWV was $11 \%$ higher in the HIV + ve/MS-ve group when compared to the HIV-ve/MS-ve group $(6.2 \pm 1.9$ vs $5.6 \pm 1.9 \mathrm{~m} / \mathrm{s}, \mathrm{p}=0.008$, Figure 2$)$ and aortic distensibility reduced (PDA by $12 \%$, AA by $14 \%$, both $\mathrm{p}<0.01$, Figure 3). Put together this suggests that HIV alone causes increased aortic stiffness. Of note, there was no difference between regional AD and PWV when comparing HAART naïve $(n=13)$ to HAART treated $(n=77)$ subjects ( $\mathrm{p}>0.2$ for all analyses).

\section{Comparing the effects of HIV and the metabolic syndrome on aortic elastic function}

In order to compare the effect of HIV and the Metabolic syndrome on PWV and AD, subjects with the metabolic syndrome but without a history of HIV infection (HIV-ve/ MS + ve, $n=44$ ) were compared to patients with HIV infection without the metabolic syndrome (HIV + ve/MS-ve, $n=73$ ). As expected, the group with metabolic syndrome had higher blood pressures, BMI, visceral fat and waist circumference when compared to the group without metabolic syndrome (Table 1). Interestingly, despite this, both the HIV-ve/MS + ve and the HIV + ve/MS-ve groups had similar PWV $(6.7 \pm 1.9$ vs $6.2 \pm 1.9 \mathrm{~m} / \mathrm{s} \mathrm{p}=0.94)$, which were $16-20 \%$ higher than the HIV-ve/MS-ve group ( $\mathrm{p}<0.05$ for both analyses). A similar pattern was seen comparing distensibility in the HIV-ve/MS + ve and the $\mathrm{HIV}+\mathrm{ve} / \mathrm{MS}$-ve with aortic distensibility measures at all three levels of the aorta being similar across the two groups 
Table 1 Anthropometric characteristics of the study population

\begin{tabular}{|c|c|c|c|c|c|}
\hline & $\begin{array}{l}\text { HIV-ve/MS-ve } \\
(n=92)\end{array}$ & $\begin{array}{l}\text { HIV-ve/MS + ve } \\
(n=44)\end{array}$ & $\begin{array}{l}\text { HIV + ve/MS-ve } \\
(n=73)\end{array}$ & $\begin{array}{l}\text { HIV + ve/MS + ve } \\
(n=17)\end{array}$ & $\begin{array}{l}P \text { value from analysis } \\
\text { of variance }\end{array}$ \\
\hline Age (years) & $45 \pm 10$ & $49 \pm 11$ & $44 \pm 10$ & $48 \pm 8$ & 0.12 \\
\hline BMI $\left(\mathrm{kg} / \mathrm{m}^{2}\right)$ & $25 \pm 4$ & $33 \pm 7^{*}$ & $25 \pm 4^{\Phi}$ & $30 \pm 6^{* 4}$ & $<0.001$ \\
\hline \multirow[t]{2}{*}{ Visceral Fat $\left(\mathrm{cm}^{2}\right)$} & $71 \pm 39$ & $160 \pm 71^{*}$ & $86 \pm 49^{\Phi}$ & $120 \pm 66^{*}$ & $<0.001$ \\
\hline & $0.9 \pm 0.5$ & $1.7 \pm 0.8^{*}$ & $1.3 \pm 1.0$ & $2.4 \pm 1.7^{* \Psi}$ & $<0.001$ \\
\hline Cholesterol (mmol/L) & $4.8 \pm 0.9$ & $5.1 \pm 1.2$ & $4.5 \pm 1.4$ & $4.6 \pm 1.4$ & 0.110 \\
\hline HDL-C (mmol/L) & $1.6 \pm 0.4$ & $1.1 \pm 0.3^{*}$ & $1.2 \pm 0.4^{*}$ & $1.0 \pm 0.4^{*}$ & $<0.001$ \\
\hline Glucose (mmol/L) & $4.8 \pm 0.5$ & $5.4 \pm 0.8^{*}$ & $5.0 \pm 0.8$ & $6.0 \pm 1.3^{* \Phi \psi}$ & $<0.001$ \\
\hline HOMA-IR & $1.1 \pm 1.0$ & $3.5 \pm 2.7^{*}$ & $1.4 \pm 1.3^{\Phi}$ & $4.6 \pm 6.1^{* 4}$ & $<0.001$ \\
\hline hs-CRP (mg/L) & $0.7 \pm 1.6$ & $3.1 \pm 4.0^{*}$ & $2.2 \pm 2.7^{*}$ & $4.6 \pm 4.5^{* 4}$ & $<0.001$ \\
\hline SBP $(\mathrm{mmHg})$ & $117 \pm 12$ & $130 \pm 14^{*}$ & $118 \pm 16^{\Phi}$ & $138 \pm 16^{* \Psi}$ & $<0.001$ \\
\hline $\mathrm{DBP}(\mathrm{mmHg})$ & $73 \pm 9$ & $80 \pm 8^{*}$ & $75 \pm 9^{\Phi}$ & $85 \pm 8^{* \Psi}$ & $<0.001$ \\
\hline Waist circumference $(\mathrm{cm})$ & $88 \pm 14$ & $110 \pm 17^{*}$ & $89 \pm 11^{\Phi}$ & $106 \pm 16^{* 4}$ & $<0.001$ \\
\hline Smoking (\%) & 32 & 32 & 37 & 41 & 0.799 \\
\hline PWV (m/s) & $5.6 \pm 1.0$ & $6.7 \pm 1.7^{*}$ & $6.2 \pm 1.9^{*}$ & $7.4 \pm 2.4^{* 4}$ & $<0.001$ \\
\hline
\end{tabular}

${ }^{*} \mathrm{p}<0.05$ versus HIV-ve/MS-ve.

${ }^{\Phi} \mathrm{p}<0.05$ versus HIV-ve/MS + ve.

$\psi_{\mathrm{p}}<0.05$ versus HIV + ve/MS-ve.

(Figure 3). This suggests HIV and the metabolic syndrome have a similar magnitude of effect on aortic elastic function.

\section{Investigating an additive effect of treated HIV and the metabolic syndrome}

To investigate whether HIV and the metabolic syndrome are additive in their negative effects on PWV, patients with HIV infection without the metabolic syndrome $(\mathrm{HIV}+\mathrm{ve} / \mathrm{MS}$-ve, $\mathrm{n}=73)$ were compared to subjects with both HIV infection and the metabolic syndrome $(\mathrm{HIV}+\mathrm{ve} / \mathrm{MS}+\mathrm{ve}, \mathrm{n}=17)$. As would be expected the $\mathrm{HIV}+\mathrm{ve} / \mathrm{MS}$ + ve group had increased BMI, SBP, DBP, waist circumference, HOMA-IR, glucose and hs-CRP when compared to the HIV+/MS-ve group (Table 1). Again, as expected, both the HIV + ve/MS-ve and the $\mathrm{HIV}+\mathrm{ve} / \mathrm{MS}$ + ve groups had higher PWV than the
HIV-ve/MS-ve group (PWV by 15\% and 38\% respectively $\mathrm{p}<0.05$ for both analyses) In agreement with this, both the $\mathrm{HIV}+\mathrm{ve} / \mathrm{MS}$-ve and the $\mathrm{HIV}+\mathrm{ve} / \mathrm{MS}+\mathrm{ve}$ groups had lower aortic distensibility than the HIV-ve/MS-ve group (Ao by $16 \%$ and $44 \%$, PDA by $20 \%$ and $45 \%$, DDA by $18 \%$ and $38 \%$, respectively all $\mathrm{p}<0.05)$. Importantly, PWV in the HIV + ve/MS + ve group was $19 \%$ higher and aortic distensibility $31 \%$, lower $(=0.011$, Figure 3$)$ than that recorded in the HIV + ve/MS-ve group $(7.4 \pm 2.4$ vs $6.2 \pm$ $1.9 \mathrm{~m} / \mathrm{s}, \mathrm{p}<0.05)$. Put together, this suggests an additive detrimental effect of HIV and the metabolic syndrome on aortic elastic function.

\section{Determinants of aortic PWV in study population}

In order to investigate the associations between PWV and other study parameters of the metabolic syndrome

Table 2 HIV specific data for the HIV + ve/MS-ve and HIV + ve/MS + ve groups, data presented as median (Interquartile range)

\begin{tabular}{|c|c|c|c|c|}
\hline & \multicolumn{2}{|l|}{ HIV + ve/MS-ve } & \multicolumn{2}{|l|}{ HIV + ve/MS + ve } \\
\hline & On HAART $(n=61)$ & No HAAR $(n=12)$ & On HAART $(n=16)$ & No HAART $(n=1)$ \\
\hline Duration of HIV infection (years) & $6(7)$ & $2(4)$ & $8(9)$ & 6 \\
\hline Time on HAART (years) & $3(5)$ & - & $6(7)$ & - \\
\hline Nadir CD4 cell count $\left(10^{6} / \mathrm{L}\right)$ & 190 (170) & $560(425)$ & 170 (190) & 300 \\
\hline Current CD4 cell count $\left(10^{6} / \mathrm{L}\right)$ & $515(218)$ & $640(400)$ & $550(255)$ & 300 \\
\hline HIV viral load (copies/mL) & $10(10)$ & $896(17,613)$ & $10(10)$ & 55,095 \\
\hline Protease inhibitors (\%) & 21 & - & 41 & - \\
\hline NRTI (\%) & 81 & - & 94 & - \\
\hline NNRTI (\%) & 61 & - & 53 & - \\
\hline
\end{tabular}




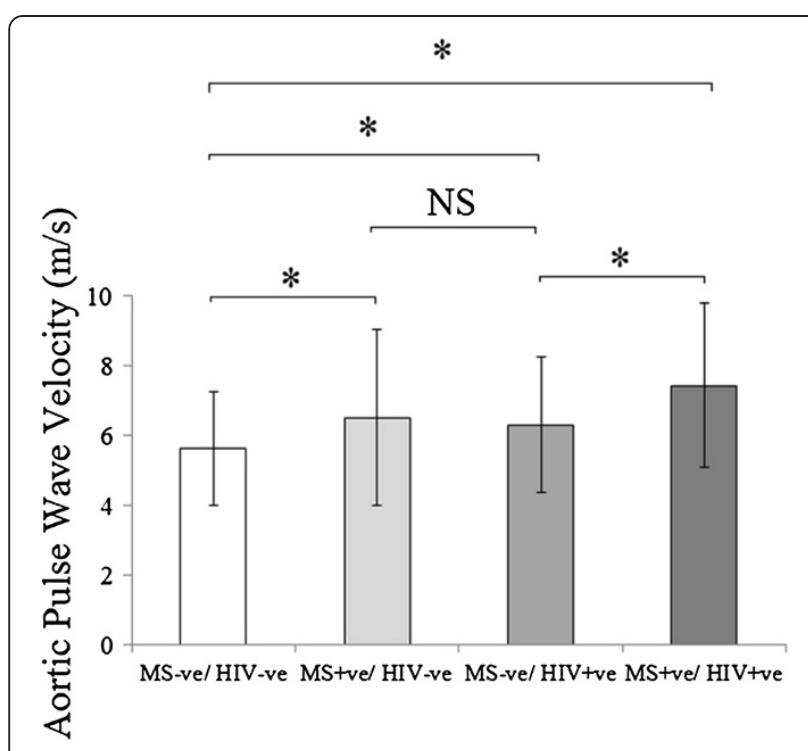

Figure 2 The effect of HIV and the metabolic syndrome on aortic pulse wave velocity.

and HIV infection, all 226 subjects were included in this analysis. Associations between anthropometric, metabolic and HIV-related characteristics and aortic PWV are presented in Table 3. In agreement with the published literature, aortic PWV was positively correlated with age, BMI, systolic blood pressure, diastolic blood pressure, waist circumference, visceral fat mass, fasting serum glucose and hs-CRP levels. Interestingly, HIV infection per se, current CD4 count and smoking status were also positively correlated with PWV. Importantly, there was no association between duration of HAART, antiretroviral class, viral load or nadir CD4 count and aortic PWV. To investigate if there were any independent predictors of pulse wave velocity, multivariable regression was used as described above. The strongest stepwise multivariable model in this study consisted of aortic pulse wave velocity as the dependent variable and age, SBP, waist circumference, fasting serum glucose, hs-CRP and HIV infection as independent variables. This showed that age $(\beta=0.065, p<0.001)$, SBP $(\beta=0.017$, $\mathrm{p}=0.043)$ and HIV infection $(\beta=0.53, \mathrm{p}=0.037)$ were all independent predictors of aortic PWV in this study group (overall $\mathrm{R}^{2}$ of the model $=0.33, \mathrm{p}<0.001$ ). This suggests that along with age and blood pressure, HIV infection is independently associated with greater aortic stiffness.

\section{Determinants of regional aortic distensibility}

In order to investigate the associations between regional $\mathrm{AD}$ and other study parameters of the metabolic syndrome and HIV infection, all 203 subjects were included in this analysis. Associations between

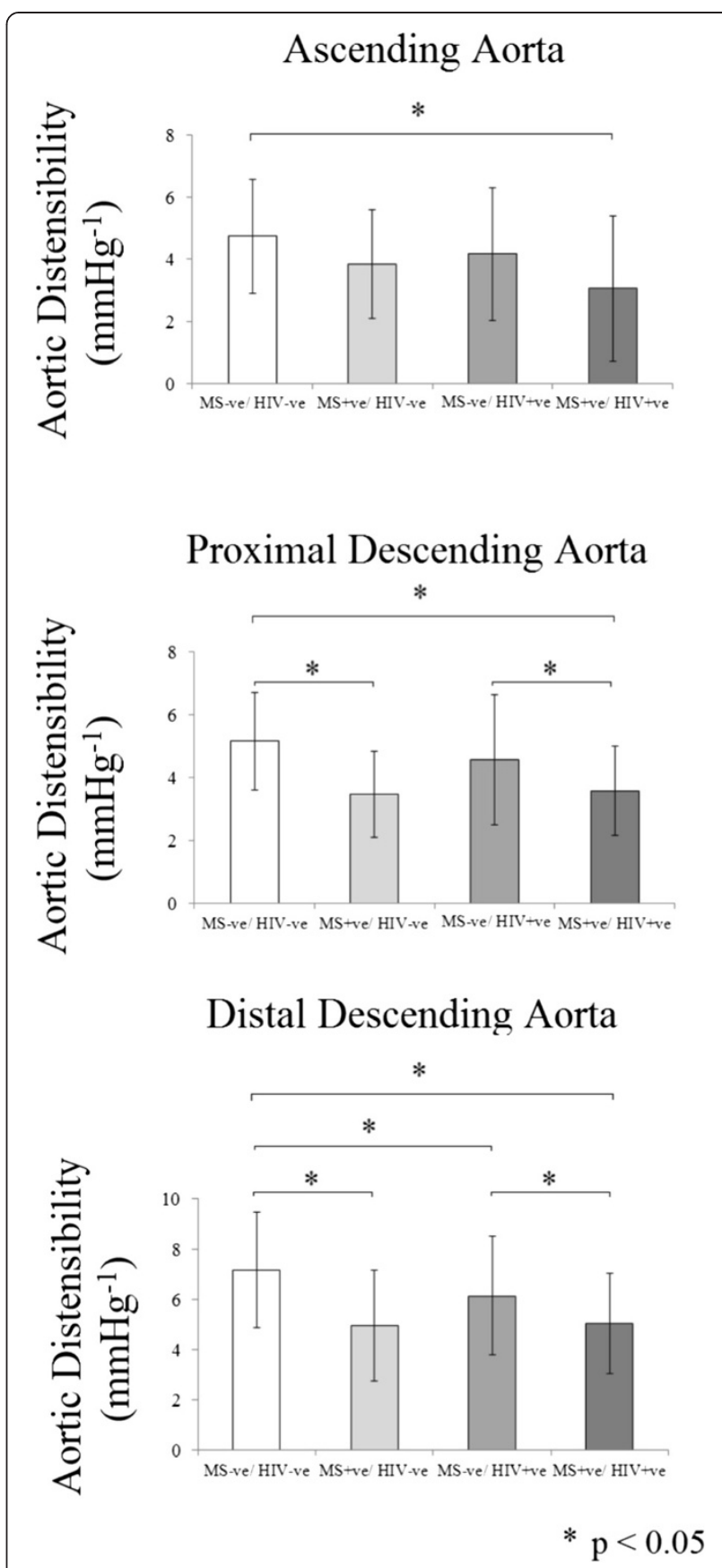

Figure 3 The effect of HIV and the metabolic syndrome on aortic distensibility. For Clarity Only Differences in Distensibility Reaching a Statistical Significance of $p<0.05$ are Highlighted.

anthropometric, metabolic and HIV-related characteristics and aortic AD are presented in Table 3. In agreement with the published literature, aortic distensibility was negatively correlated with age, systolic blood pressure, diastolic blood pressure, visceral fat mass, fasting serum glucose and hs-CRP levels at all levels measured. Importantly, HIV infection was also associated with 
Table 3 Associations between PWV and study characteristics of HIV and the metabolic syndrome

\begin{tabular}{|c|c|c|c|c|c|c|c|c|}
\hline & & & Aortic & ensibility & $\left.\mathrm{nHg}^{-1}\right)$ & & & \\
\hline & Pulse & locity & Ascen & & Proxi & ending & Abdo & \\
\hline & $r$ & $\mathbf{p}$ & $\mathbf{r}$ & $\mathbf{p}$ & $\mathbf{r}$ & p & $r$ & $\mathbf{p}$ \\
\hline Age (years) & 0.52 & $<0.001$ & -0.41 & $<0.001$ & -0.37 & $<0.001$ & -0.29 & $<0.001$ \\
\hline BMI $\left(\mathrm{kg} / \mathrm{m}^{2}\right)$ & 0.20 & 0.043 & -0.15 & 0.11 & -0.23 & $<0.001$ & -0.22 & $<0.001$ \\
\hline Visceral Fat $\left(\mathrm{cm}^{2}\right)$ & 0.24 & 0.008 & -0.09 & 0.28 & -0.25 & $<0.001$ & -0.22 & 0.01 \\
\hline Glucose $(\mathrm{mmol} / \mathrm{l})$ & 0.15 & 0.049 & -0.13 & 0.12 & -0.24 & $<0.001$ & -0.17 & 0.03 \\
\hline Triglycerides (mmol/L) & 0.13 & 0.09 & -0.07 & 0.37 & -0.20 & 0.01 & -0.24 & $<0.001$ \\
\hline HDL-C (mmol/L) & -0.14 & 0.07 & 0.01 & 0.99 & 0.08 & 0.34 & 0.09 & 0.26 \\
\hline hsCRP (mg/L) & 0.33 & $<0.001$ & -0.14 & 0.01 & -0.30 & $<0.001$ & -0.26 & $<0.001$ \\
\hline SBP $(\mathrm{mmHg})$ & -0.27 & $<0.001$ & -0.29 & $<0.001$ & -0.32 & $<0.001$ & -0.36 & $<0.001$ \\
\hline $\mathrm{DBP}(\mathrm{mmHg})$ & 0.20 & $<0.001$ & -0.17 & $<0.02$ & -0.21 & $<0.001$ & -0.23 & $<0.001$ \\
\hline Waist circumference $(\mathrm{cm})$ & 0.19 & 0.02 & -0.15 & 0.08 & -0.21 & $<0.001$ & -0.31 & $<0.001$ \\
\hline Cholesterol (mmol/L) & 0.13 & 0.87 & -0.12 & 0.14 & -0.16 & 0.04 & -0.11 & 0.18 \\
\hline HOMA-IR & 0.09 & 0.39 & -0.08 & 0.35 & -0.15 & 0.06 & -0.15 & 0.05 \\
\hline Past or present smoking & 0.28 & $<0.001$ & -0.17 & 0.03 & -0.18 & 0.03 & -0.10 & 0.20 \\
\hline Viral load (copies/mL) & 0.06 & 0.56 & -0.12 & 0.30 & -0.12 & 0.29 & -0.04 & 0.69 \\
\hline Nadir CD4 count $\left(10^{6} / \mathrm{L}\right)$ & -0.13 & 0.30 & -0.06 & 0.62 & 0.09 & 0.42 & 0.16 & 0.17 \\
\hline Current $\mathrm{CD} 4$ count $\left(10^{6} / \mathrm{L}\right)$ & 0.26 & 0.014 & -0.14 & 0.23 & -0.02 & 0.83 & -0.05 & 0.67 \\
\hline PIs & 0.06 & 0.51 & 0.11 & 0.23 & 0.03 & 0.75 & -0.11 & 0.24 \\
\hline NRTIs & 0.11 & 0.22 & -0.10 & 0.27 & -0.17 & 0.08 & -0.22 & 0.02 \\
\hline NNRTIs & 0.05 & 0.58 & -0.18 & 0.06 & -0.18 & 0.05 & -0.12 & 0.18 \\
\hline Duration of HAART (years) & 0.20 & 0.09 & -0.12 & 0.36 & -0.07 & 0.57 & -0.10 & 0.42 \\
\hline HIV infection & 0.23 & 0.001 & -0.21 & 0.01 & -0.25 & $<0.001$ & -0.21 & 0.01 \\
\hline
\end{tabular}

reduced distensibility at all three levels measured. In addition, as expected, BMI, waist circumference and triglyceride levels were negatively correlated with proximal descending and negatively with distal descending thoracic aortic distensibility (Table 3). In a similar pattern to that seen with PWV, there was no association between duration of HAART, antiretroviral class, viral load or nadir CD4 count and aortic AD. To investigate if there were any independent predictors of pulse wave velocity, multivariable regression was used as described above. The strongest stepwise multivariable models in this study consisted of aortic distensibility (Ao, PDA, DDA) as the dependent variables and age, BMI, SBP, fasting serum glucose, presence of the metabolic syndrome, smoking status and HIV infection as independent variables. This showed that age (Ao $\beta=-0.108$, PDA $\beta=-0.05$, DDA $\beta=-0.06$, all $\mathrm{p}<0.001$ ), SBP (Ao $\beta=-0.09$, PDA $\beta=-0.03$, DDA $\beta=-0.04$, all $p<0.01)$ and HIV infection (Ao $\beta=-0.41$, PDA $\beta=-0.08$, DDA $\beta=-1.2$, all $\mathrm{p}<0.02)$ were all independent predictors of aortic AD at all levels measured. In addition, again as expected BMI was an independent predictor of DDA $(\beta=-0.12$, $\mathrm{p}=0.001$ ). Overall $\mathrm{R}^{2}$ of the models; Ao $=0.48$, PDA 0.43, DDA 0.39, all $\mathrm{p}<0.001$. This suggests that along with age, blood pressure and BMI, HIV infection is independently associated with increased aortic stiffness.

\section{Discussion}

This study has shown that, after matching for potential confounders, HIV infection is independently associated with increased aortic PWV and decreased aortic distensibility, both sensitive markers of reduced aortic elastic function. In addition HIV infection is an independent predictor of both increased pulse wave velocity and decreased aortic distensibility, clinical measures of aortic stiffness linked to increased cardiovascular mortality. The size of this detrimental effect is similar to that seen with the metabolic syndrome, a powerful cardiovascular risk factor. We have shown that HIV and the metabolic syndrome are additive in their negative effects on PWV and aortic distensibility, suggesting that both are risk factors that act in different ways to impair vascular elasticity. The mechanism of vascular alterations in patients with HIV may be secondary to direct effects of the HIV virus on vascular function, including direct alteration in endothelial function, inflammation, and modification of aortic wall vascular smooth muscle cell behaviour and extra-cellular matrix composition. 


\section{Chronic inflammation}

There is significant evidence that HIV infection is associated with chronic systemic and vascular inflammation even in patients on stable HAART with preserved CD4 counts and HIV RNA levels $<50$ copies/ml, $[8,26]$ and these patients also have a greater burden of subclinical atherosclerosis [7]. Elevations in inflammatory markers, such as CRP, are associated with both increased arterial stiffness [27] and a higher risk of mortality [28]. In support of a chronic inflammatory HIV-related vasculopathy explaining our findings, a recent 18 F-FDG-PET study demonstrated signs of increased arterial inflammation in treated subjects with HIV [8]. Moreover, hsCRP was not only elevated in patients with HIV in this study but was also positively correlated to aortic PWV and negatively correlated to AD at all three levels, and furthermore was strongly correlated with visceral fat, which is thought to play a central role in this inflammatory process, with macrophage release of IL- 6 and TNF- $\alpha$ [29] both which are associated with increased PWV. This may suggest a role for elevated visceral fat in vascular elastic dysfunction in treated HIV [30].

This study has demonstrated impaired vascular function in HIV subjects, independent of traditional risk factors, and, together with other studies of contemporary cohorts of patients with treated HIV, suggest that chronic inflammation in HIV infection may partially underlie the reduced vascular function and premature atherosclerosis. Prospective studies to reduce chronic inflammation beyond HAART are required to investigate whether or not this improves vascular inflammation and function and ultimately reduces atherosclerotic risk in patients with HIV.

\section{Endothelial dysfunction in HIV}

Endothelial dysfunction is a common feature of atherosclerosis [31]. There is a growing body of evidence suggesting HIV itself may have deleterious effects on endothelial function. Patients with HIV (but without the metabolic syndrome) have been shown to have reduced vascular reactivity in a pattern similar to that seen in type 2 diabetes mellitus [32]. The direct effect of HIV on endothelial biology has been extensively investigated. As a result of increased secretion of monocyte chemo-attractant protein 1 [33] and increased expression of the adhesion molecules, vascular cell adhesion molecule-1 (VCAM-1) intercellular adhesion molecule 1 and E-selectin [6], vascular endothelium from patients with HIV have increased monocyte adherence and monocyte migration into the vascular intima during atherosclerotic plaque development [34]. In addition, several HIV proteins, notably Tat and gp120 are themselves associated with endothelial cell activation and increased expression cell adhesion molecules [35]. Put together with the evidence that HIV infection affects lipid processing [5] and is associated with lower HDL cholesterol, lower apolipoprotein B levels (in advanced disease) [36] and smaller LDL cholesterol particles, this environment provides an atherogenic milieu [37]. Although studies have now shown that HAART may to some extent reduce endothelial activation, it does not appear to completely ameliorate the effects of HIV infection, suggesting that even during complete virological suppression, endothelial dysfunction persists and continues to promote atherosclerosis (and excess cardiovascular risk) in $\operatorname{HIV}[38,39]$.

\section{The additive effect of treated HIV infection and the metabolic syndrome on arterial stiffness}

The detrimental effect of the metabolic syndrome on aortic stiffness is well established [40-42]. This study has not only shown that treated HIV infection has a similar sized effect on aortic stiffness to the metabolic syndrome, but has also shown that the combination of HIV and the metabolic syndrome are additive in their negative effects. This suggests that patients with both are likely to be at even higher risk of cardiovascular events. As hs-CRP was significantly higher in HIV subjects with the MS compared to HIV subjects without the MS, and CRP has been shown to be a marker of excess risk, [41] inflammation is a potential unifying mechanism that may underlie the pathogenesis of vascular disease in both groups.

\section{Study limitations}

Due to the observational nature of this study, it is not possible to confirm causality or mechanisms which might underlie the increased aortic PWV and decreased aortic distensibility in patients with HIV. The study was not powered to detect differences in HAART-naïve and treated subjects. Nor was it possible to determine the effects of individual anti-retroviral medications on vascular function. Given the beneficial effect of antiretroviral treatments on the vasculature and improved markers of vascular function that are observed after commencement of antiretroviral therapy [38,43], antiretroviral agents are an unlikely cause of the vascular dysfunction. Nevertheless, longitudinal studies are needed to investigate this further. However, by including both HAART naïve and HAART treated patients this study provides a representative dataset of HIV infected subjects in the UK.

Distensibility was calculated using pulse pressure measurements taken from brachial blood pressure rather than central blood pressure recordings. Although we accept central pressure recording may have changed the absolute aortic distensibility measures, given the magnitude of the changes the DDA segment (i.e. up to $45 \%$ change in distensibility), the pattern of change, i.e. the main finding of this paper would not be expected to be affected. 


\section{Conclusion}

Given the increase in cardiovascular events and cardiovascular related mortality in HIV-infected patients treated with effective antiretroviral therapy, identifying those at higher cardiovascular risk is of great clinical importance. We have shown that patients with treated HIV have reduced vascular function, which is independent of the metabolic syndrome and other traditional cardiovascular risk factors, suggesting a virus-related aetiology, such as chronic inflammation. Importantly we have shown that the magnitude of the effect of treated HIV infection is the same as that of the metabolic syndrome, a well-established and powerful predictor of cardiovascular mortality. Given the additive effect of HIV and the metabolic syndrome on reducing vascular function, aggressive management of both HIV and the metabolic syndrome are likely needed to reduce the high incidence of vascular disease in this population.

\section{Competing interests}

The authors declare that they have no competing interests.

\section{Authors' contributions}

$\mathrm{OR}, \mathrm{SN}, \mathrm{CH}, \mathrm{KC}$, LD made substantial contributions to conception and design of the study. $\mathrm{CJH}, \mathrm{NN}, \mathrm{RB}, \mathrm{AP}, \mathrm{OR}$ acquired the CMR data. EW, GH, LD acquired the HIV data. OR, MA analysed and interpreted the data. OR, MA drafted the manuscript. LD, GC, KS, OR, CH revised the manuscript critically for important intellectual content. All authors read and approved the final manuscript.

\section{Funding}

Cameron Holloway would like to acknowledge support from the Oxford NIHR Biomedical Research Centre programme and the Australian Heart Foundation. Stefan Neubauer acknowledges support from the BHF Centre of Research. The British Heart Foundation (FS07/030) supported this work. The research was supported by the National Institute for Health Research (NIHR) Oxford Biomedical Research Centre based at The Oxford University Hospitals Trust at the University of Oxford.

\section{Author details}

'Department of Physiology, Anatomy and Genetics, University of Oxford, Parks Road, Oxford OX1 3PT, UK. ²Department of Cardiovascular Medicine, University of Oxford Centre for Clinical Magnetic Resonance Research, (OCMR), John Radcliffe Hospital, Oxford OX3 9DU, UK. ${ }^{3}$ Oxford NIHR Biomedical Research Centre, University of Oxford, Oxford, UK. ${ }^{4}$ St Vincent's Hospital, Sydney, Australia.

Received: 28 March 2014 Accepted: 16 July 2014

Published online: 16 August 2014

\section{References}

1. Sterne JA, Hernan MA, Ledergerber B, Tilling $K$, Weber $R$, Sendi $P$, Rickenbach M, Robins JM, Egger M. Long-term effectiveness of potent antiretroviral therapy in preventing AIDS and death: a prospective cohort study. Lancet. 2005; 366:378-84.

2. Triant VA, Lee H, Hadigan C, Grinspoon SK. Increased acute myocardial infarction rates and cardiovascular risk factors among patients with human immunodeficiency virus disease. J Clin Endocrinol Metab. 2007; 92:2506-12.

3. Grunfeld C, Delaney JAC, Wanke C, Currier JS, Scherzer R, Biggs ML, Tien PC, Shlipak MG, Sidney S, Polak JF, O'Leary D, Bacchetti P, Kronmal RA, Cha SFRM. Preclinical atherosclerosis due to HIV infection: carotid intima-medial thickness measurements from the FRAM study. AIDS. 2009; 23:1841-49.
4. Tseng ZH, Secemsky EA, Dowdy D, Vittinghoff E, Moyers B, Wong JK, Havlir DV, Hsue PY. Sudden cardiac death in patients with human immunodeficiency virus infection. J Am Coll Cardiol. 2012; 59:1891-96.

5. Riddler SA, Smit E, Cole SR, Li R, Chmiel JS, Dobs A, Palella F, Visscher B, Evans R, Kingsley LA. Impact of HIV infection and HAART on serum lipids in men. JAMA. 2003; 289:2978-82.

6. Fisher SD, Miller TL, Lipshultz SE. Impact of HIV and highly active antiretroviral therapy on leukocyte adhesion molecules, arterial inflammation, dyslipidemia, and atherosclerosis. Atherosclerosis. 2006; 185:1-11.

7. Hsue PY, Hunt PW, Schnell A, Kalapus SC, Hoh R, Ganz P, Martin JN, Deeks SG. Role of viral replication, antiretroviral therapy, and immunodeficiency in HIV-associated atherosclerosis. AIDS. 2009; 23:1059-67.

8. Subramanian S, Tawakol A, Burdo TH, Abbara S, Wei J, Vijayakumar J, Corsini E, Abdelbaky A, Zanni MV, Hoffmann U, Williams KC, Lo J, Grinspoon SK. Arterial inflammation in patients with HIV. JAMA. 2012; 308:379-86.

9. Samaras K. Prevalence and pathogenesis of diabetes mellitus in HIV-1 infection treated with combined antiretroviral therapy. J Acquir Immune Defic Syndr. 2009; 50:499-505.

10. Badiou S, De Boever CM, Dupuy AM, Baillat V, Cristol JP, Reynes J. Small dense LDL and atherogenic lipid profile in HIV-positive adults: influence of lopinavir/ritonavir-containing regimen. AIDS. 2003; 17:772-74.

11. Sabin CA, Worm SW, Weber R, Reiss P, El-Sadr W, Dabis F, De Wit S, Law M, D'Arminio Monforte A, Friis-Moller N, Kirk O, Pradier C, Weller I, Phillips AN, Lundgren JD. Use of nucleoside reverse transcriptase inhibitors and risk of myocardial infarction in HIV-infected patients enrolled in the D:A:D study: a multi-cohort collaboration. Lancet. 2008; 371:1417-26.

12. Friis-Moller N, Sabin CA, Weber R, d'Arminio Monforte A, El-Sadr WM, Reiss $P$, Thiebaut R, Morfeldt L, De Wit S, Pradier C, Calvo G, Law MG, Kirk O, Phillips AN, Lundgren JD. Combination antiretroviral therapy and the risk of myocardial infarction. N Engl J Med. 2003; 349:1993-2003.

13. Klein D, Hurley LB, Quesenberry CP Jr, Sidney S. Do protease inhibitors increase the risk for coronary heart disease in patients with HIV-1 infection? J Acquir Immune Defic Syndr. 2002; 30:471-77.

14. Sutton-Tyrrell K, Newman A, Simonsick EM, Havlik R, Pahor M, Lakatta E, Spurgeon $H$, Vaitkevicius $P$. Aortic stiffness is associated with visceral adiposity in older adults enrolled in the study of health, aging, and body composition. Hypertension. 2001; 38:429-33.

15. Mattace-Raso FU, van der Cammen TJ, Hofman A, van Popele NM, Bos ML, Schalekamp MA, Asmar R, Reneman RS, Hoeks AP, Breteler MM, Witteman JC. Arterial stiffness and risk of coronary heart disease and stroke: the Rotterdam Study. Circulation. 2006; 113:657-63.

16. Taniwaki H, Kawagishi T, Emoto M, Shoji T, Kanda H, Maekawa K, Nishizawa $Y$, Morii H. Correlation between the intima-media thickness of the carotid artery and aortic pulse-wave velocity in patients with type 2 diabetes. Vessel wall properties in type 2 diabetes. Diabetes Care. 1999; 22:1851-57.

17. Third Report of the National Cholesterol Education Program (NCEP) Expert Panel on Detection, Evaluation, and Treatment of High Blood Cholesterol in Adults (Adult Treatment Panel III) final report. Circulation. 2002; 106:3143-421.

18. Matthews DR, Hosker JP, Rudenski AS, Naylor BA, Treacher DF, Turner RC. Homeostasis model assessment: insulin resistance and beta-cell function from fasting plasma glucose and insulin concentrations in man. Diabetologia. 1985; 28:412-19.

19. Wiesmann F, Petersen SE, Leeson PM, Francis JM, Robson MD, Wang Q, Choudhury R, Channon KM, Neubauer S. Global impairment of brachial, carotid, and aortic vascular function in young smokers: direct quantification by high-resolution magnetic resonance imaging. J Am Coll Cardiol. 2004; 44:2056-64.

20. Rider OJ, Holloway CJ, Emmanuel Y, Bloch E, Clarke K, Neubauer S. Increasing plasma free fatty acids in healthy subjects induces aortic distensibility changes seen in obesity. Circ Cardiovasc Imaging. 2012; 5:367-75.

21. Lewandowski AJ, Lazdam M, Davis E, Kylintireas I, Diesch J, Francis J, Neubauer S, Singhal A, Lucas A, Kelly B, Leeson P. Short-term exposure to exogenous lipids in premature infants and long-term changes in aortic and cardiac function. Arterioscler Thromb Vasc Biol. 2011; 31:2125-35.

22. Rider OJ, Francis JM, Ali MK, Petersen SE, Robinson M, Robson MD, Byrne JP, Clarke K, Neubauer S. Beneficial cardiovascular effects of bariatric surgical and dietary weight loss in obesity. J Am Coll Cardiol. 2009; 54:718-26.

23. Leeson CP, Robinson M, Francis JM, Robson MD, Channon KM, Neubauer $S$, Wiesmann F. Cardiovascular magnetic resonance imaging for non- 
invasive assessment of vascular function: validation against ultrasound. J Cardiovasc Magn Reson. 2006; 8:381-87.

24. Rider OJ, Tayal U, Francis JM, Ali MK, Robinson MR, Byrne JP, Clarke K, Neubauer $\mathrm{S}$. The effect of obesity and weight loss on aortic pulse wave velocity as assessed by magnetic resonance imaging. Obesity. 2010; 18:2311-16.

25. Rider OJ, Francis JM, Ali MK, Byrne J, Clarke K, Neubauer S, Petersen SE. Determinants of left ventricular mass in obesity; a cardiovascular magnetic resonance study. J Cardiovasc Magn Reson. 2009; 11:9.

26. Kuller LH, Tracy R, Belloso W, De Wit S, Drummond F, Lane HC, Ledergerber B, Lundgren J, Neuhaus J, Nixon D, Paton NI, Neaton JD, Group ISS. Inflammatory and coagulation biomarkers and mortality in patients with HIV infection. PLoS Med. 2008; 5:e203.

27. Yasmin MECM, Wallace S, Mackenzie IS, Cockcroft JR, Wilkinson IB. C-reactive protein is associated with arterial stiffness in apparently healthy individuals. Arterioscler Thromb Vasc Biol. 2004; 24:969-74.

28. Tuomisto K, Jousilahti P, Sundvall J, Pajunen P, Salomaa V. C-reactive protein, interleukin- 6 and tumor necrosis factor alpha as predictors of incident coronary and cardiovascular events and total mortality. A population-based, prospective study. Thromb Haemost. 2006; 95:511-18.

29. Van Gaal LF, Mertens IL, De Block CE. Mechanisms linking obesity with cardiovascular disease. Nature. 2006; 444:875-80.

30. Pauletto $P$, Rattazzi M. Inflammation and hypertension: the search for a link. Nephrol Dial Transplant. 2006; 21:850-53.

31. Shimokawa H. Primary endothelial dysfunction: atherosclerosis. J Mol Cell Cardiol. 1999; 31:23-37.

32. van Wijk JP, de Koning EJ, Cabezas MC, Joven J, op't Roodt J, Rabelink TJ, Hoepelman AM. Functional and structural markers of atherosclerosis in human immunodeficiency virus-infected patients. J Am Coll Cardiol. 2006; 47:1117-23.

33. Park IW, Wang JF, Groopman JE. HIV-1 Tat promotes monocyte chemoattractant protein-1 secretion followed by transmigration of monocytes. Blood. 2001; 97:352-58.

34. Zietz C, Hotz B, Sturzl M, Rauch E, Penning R, Lohrs U. Aortic endothelium in HIV-1 infection: chronic injury, activation, and increased leukocyte adherence. Am J Pathol. 1996; 149:1887-98.

35. $\mathrm{Mu} \mathrm{H}$, Chai H, Lin PH, Yao Q, Chen C. Current update on HIV-associated vascular disease and endothelial dysfunction. World J Surg. 2007; 31:632-43.

36. Shahmanesh M, Das S, Stolinski M, Shojaee-Moradie F, Jackson NC, Jefferson W, Cramb R, Nightingale P, Umpleby AM. Antiretroviral treatment reduces very-low-density lipoprotein and intermediate-density lipoprotein apolipoprotein B fractional catabolic rate in human immunodeficiency virus-infected patients with mild dyslipidemia. J Clin Endocrinol Metab. 2005; 90:755-60.

37. Mujawar Z, Rose H, Morrow MP, Pushkarsky T, Dubrovsky L, Mukhamedova N, Fu Y, Dart A, Orenstein JM, Bobryshev YV, Bukrinsky M, Sviridov D. Human immunodeficiency virus impairs reverse cholesterol transport from macrophages. PLoS Biol. 2006; 4:e365.

38. van Vonderen MG, Hassink EA, van Agtmael MA, Stehouwer CD, Danner SA, Reiss $P$, Smulders $Y$. Increase in carotid artery intima-media thickness and arterial stiffness but improvement in several markers of endothelial function after initiation of antiretroviral therapy. I Infect Dis. 2009; 199:1186-94.

39. Wolf K, Tsakiris DA, Weber R, Erb P, Battegay M, Swiss HIVCS. Antiretroviral therapy reduces markers of endothelial and coagulation activation in patients infected with human immunodeficiency virus type 1. J Infect Dis. 2002; 185:456-62.

40. Tsubakimoto A, Saito I, Mannami T, Naito Y, Nakamura S, Dohi Y, Yonemasu $\mathrm{K}$. Impact of metabolic syndrome on brachial-ankle pulse wave velocity in Japanese. Hypertens Res. 2006; 29:29-37.

41. Tomiyama H, Koji Y, Yambe M, Motobe K, Shiina K, Gulnisa Z, Yamamoto Y, Yamashina A. Elevated C-reactive protein augments increased arterial stiffness in subjects with the metabolic syndrome. Hypertension. 2005; 45:997-1003.
42. Reilly MP, Rader DJ. The metabolic syndrome: more than the sum of its parts? Circulation. 2003; 108:1546-51.

43. Torriani FJ, Komarow L, Parker RA, Cotter BR, Currier JS, Dube MP, Fichtenbaum CJ, Gerschenson M, Mitchell CK, Murphy RL, Squires K, Stein $J$. Endothelial function in human immunodeficiency virus-infected antiretroviral-naive subjects before and after starting potent antiretroviral therapy: The ACTG (AIDS Clinical Trials Group) Study 5152s. J Am Coll Cardiol. 2008; 52:569-76.

doi:10.1186/s12968-014-0057-1

Cite this article as: Rider et al:: HIV is an independent predictor of aortic stiffness. Journal of Cardiovascular Magnetic Resonance 2014 16:57.

\section{Submit your next manuscript to BioMed Central and take full advantage of:}

- Convenient online submission

- Thorough peer review

- No space constraints or color figure charges

- Immediate publication on acceptance

- Inclusion in PubMed, CAS, Scopus and Google Scholar

- Research which is freely available for redistribution

Submit your manuscript at www.biomedcentral.com/submit
( Biomed Central 